\title{
Editorial
}

\section{Surface Physics 1987}

\section{(Oberflächenphysik 1987)}

Igls bei Innsbruck, Austria, 16th-19th March 1987

Co-chairmen: A. M. Bradshaw (Berlin)

M. Landolt (Zürich)

F. Netzer (Innsbruck)
Local Organizing Committee: H. Gruber

K. Hayek

F. Netzer

A. Weber

The papers in this special issue of Applied Physics $A$ are the invited talks and post-deadline contributions at the joint spring meeting of the surface physics sections of the German Physical Society and the Austrian and Swiss Vacuum Societies, held at Igls near Innsbruck, Austria, 16th-19th March 1987. The topics covered by the invited papers include spinpolarised photoemission, surface magnetism, ion scattering, LEED microscopy, polymer surfaces and chemisorption. Inverse photoemission studies on physisorbed xenon and photoelectron spectroscopy of high temperature superconductors were among the subjects which attracted considerable interest during the post-deadline session. Of the 176 contributed papers over half were concerned with adsorbates, particularly with geometric structure, but also with electronic and vibrational properties. New work with the scanning tunnelling microscope (STM) was described; of particular interest is the failure to observe pure adsorbate structures without concomitant surface reconstruction. The potential applications of the STM in spectroscopy, particularly in the investigation of unfilled adsorbate levels, were, however, clearly apparent. Abstracts of all papers presented at the meeting have been published in Verhandl. DPG (VI) 22 (1987).

Just before going to press we learnt with great sadness of the tragic death of Wolfgang Telieps, an invited speaker at the Igls meeting. The talk on the LEED microscope was undoubtedly a highlight of the conference. His untimely death is a great loss for the surface physics community in Germany. 